\title{
Arachidonate Metabolism in Bovine Gallbladder Mucosa
}

\author{
TOSHIHIRO HIDAKA, MITSURO NAKANO, TAKAHIRO INOKUCHI*, \\ MASAYASU SUGIYAMA, JUICHI NISHI AND RYOHEI OGURA
Department of Medical Biochemistry and Institute of Medical Mass Spectrometry*, Kurume University School of Medicine, Kurume, 830 Japan

Received for publication May 27, 1991

\begin{abstract}
Summary: Incubation of $\left[1 .{ }^{14} \mathrm{C}\right]$ arachidonicacid (AA) with homogenates of bovine gallbladder mucosa in the presence or absence of reduced glutathione (GSH) generated large amounts of products that cochromatographed with $\mathrm{PGE}_{2}$ and 6-keto- $\mathrm{PGF}_{1} \alpha$ and small amounts of products comigrating with $\mathrm{PGF}_{2} \alpha, \mathrm{TxB}_{2}$ and $\mathrm{PGD}_{2}$. In the presence of $\mathrm{GSH} \mathrm{PGE}_{2}$-like material was predominantly produced while in the absence of GSH 6 -keto-PGF $1 \alpha$-like material was a major product. Identification of $\mathrm{PGE}_{2}$ was performed by its chemical conversion with $\mathrm{NaBH}_{4}$ or KOH treatments and by gas chromatography-mass spectrometry. Identification of 6 -keto- $\mathrm{PGF}_{1 \alpha}$ was confirmed by gas chromatography-mass spectrometry. Gallbladder muscle produced predominantly 6 -keto- $\mathrm{PGF}_{1} \alpha$ in the presence or absence of GSH. The total amount of cyclooxygenase products was approximately 2 times higher in the mucosa than in the muscle. These results indicate that bovine gallbladder mucosa contains higher levels of fatty acid cyclooxygenase, and $\mathrm{PGE}_{2}$ isomerase and $\mathrm{PGI}_{2}$ synthetase in a proportion different from that in the muscle.
\end{abstract}

Key words: prostaglandins - arachidonic acid - gallbladder mucosa - gallbladder muscle - glutathione

\section{Introduction}

In mammalian gallbladders prostaglandins (PGs) are presumed to play significant roles in fluid transport, mucin secretion and stone formation (Morton et al. 1974; Lee et al. 1981) which are directly associated with mucosal functions. However, PG biosynthesis in the mucosal layers of gallbladders has not been well characterized. Thus, we examined the metabolism of arachidonic acid (AA) in the mucosal layers of bovine gallbladders.

\section{Materials and Methods}

\section{Materials}

$\left[1-{ }^{14} \mathrm{C}\right] \mathrm{AA}(52 \mathrm{Ci} / \mathrm{mol})$ and $[5,6,8,11$, $\left.12,14,15-{ }^{3} \mathrm{H}-(\mathrm{N})\right] \mathrm{PGE}_{2}(130 \mathrm{Ci} / \mathrm{m} \mathrm{mol})$ were purchased from New England Nuclear (Boston), AA and indomethacin from Sigma Chemical Co., imidazole and reduced glutathione (GSH) from Tokyo Kasei, and TLC plates of silica gel 60 $(0.25 \mathrm{~mm}, 20 \times 20 \mathrm{~cm})$ from F. Merck (Darmstadt). Authentic PG standards and 15-hydroperoxy-arachidonic acid (15HPAA) were gifts from Ono Pharmaceutical Company. All other reagents were of the highest grade commercially available.

Preparation of homogenates of mucosal and muscle layers from bovine gallbladders

Bovine gallbladders were obtained from 
a local slaughterhouse. The gallbladder was isolated and rinsed with ice-cold saline to remove bile. Mucosal and muscle layers were separated with scissors and tweezers. Serosal and fatty layers were discarded. Tissue sample was homogenized with the same volume of $0.05 \mathrm{M}$ Tris- $\mathrm{HCl}$ buffer ( $\mathrm{pH} \mathrm{8.0)}$ containing $0.15 \mathrm{M} \mathrm{NaCl}$ and $0.5 \mathrm{mM}$ dithiothreitol using an Ultra-Turrax homogenizer, and the homogenate was centrifuged at $600 \times \mathrm{g}$ for $15 \mathrm{~min}$ to remove tissue debris. The supernatant was used as an enzyme preparation.

\section{Assay system for PG biosynthesis}

PG biosynthesis was examined as previously described (Nakano et al. 1983). In brief, the homogenate ( $40 \mathrm{mg}$ protein $/ \mathrm{ml}$ ) was incubated with $20 \mu \mathrm{M}\left[1{ }^{14} \mathrm{C}\right]$ arachidonic acid $(400,000 \mathrm{dpm})$ in $10 \mathrm{mM}$ Tris$\mathrm{HCl}$ buffer, $\mathrm{pH} 8.0$, containing $2 \mathrm{mM}$ $\mathrm{GSH}$ in a final volume of $2 \mathrm{ml}$. Reaction was started by adding the substrate dissolved in $20 \mu \mathrm{l}$ of ethanol, and continued for $5 \mathrm{~min}$ at $37^{\circ} \mathrm{C}$ with vigorous shaking. The reaction was stopped by acidifying the mixture to $\mathrm{pH} 3$ with formic acid, and radioactive metabolites were extracted with ethyl ether followed by ethyl acetate. The solvent was evaporated under $\mathrm{N}_{2}$ gas stream, and the dried residue was applied to a TLC plate together with authentic $\mathrm{PGE}_{2}, \mathrm{PGF}_{2} \alpha, 6$-keto- $\mathrm{PGF}_{1} \alpha$, $\mathrm{PGD}_{2}, \mathrm{PGB}_{2}$ and $\mathrm{AA}$. The plate was developed by using the organic phase of the solvent system: isooctane-ethyl acetate-acetic acid-water $(25: 55: 10: 50$, by volume). Radioactivity on the plate was monitored with an Aloka radiochromatogram scanner model TLC-101 or by autoradiography, and radioactivity of scraped silica gel was counted in an Aloka model LSC 673 liquid scintillation counter. Standard PG spots were visualized with iodine vapor.
Gas chromatography-mass spectrometry (GC$M S)$

PGs in the sample were derivatized with diazomethane in ether: methanol $(9: 1)$, methoxyamine $\mathrm{HCl}$ in pyridine (5 $\mathrm{mg} / \mathrm{ml}$ ) and $\mathrm{N}$, O-trimethylsilyl acetamide (BSA) - trimethyl-chlorosilane (TMCS) before analyses with a JOEL JMS-D100 combined gas chromatograph - mass spectrometer. The 2 -meter column (1\% OV-1 on Shimalate-W) was kept at $210^{\circ} \mathrm{C}$, the flash-heater at $280^{\circ} \mathrm{C}$, and the separator at $280^{\circ} \mathrm{C}$. Electron energy was set at $30 \mathrm{eV}$.

\section{Results}

A homogenate prepared from mucosa and muscle of gallbladder was incubated with $\left[1-{ }^{14} \mathrm{C}\right] \mathrm{AA}$ in the presence or absence of GSH. Extract from the reaction mixture was examined by TLC. As shown in Fig. 1A-D, five radiolabeled products (compounds I-V) were formed cochromatographig with 6-keto-PGF $1 \alpha, \mathrm{PGF}_{2} \alpha$, $\mathrm{TxB}_{2}, \mathrm{PGE}_{2}$ and $\mathrm{PGD}_{2}$. Of the total radioactivity recovered from the TLC plates, products I , II, III, IV and V formed in the presence of GSH accunted for 2.1 $\pm 0.7, \quad 0.9 \pm 0.1, \quad 0.7 \pm 0.1, \quad 4.9 \pm 0.8$ and $1.0 \pm 0.6 \%$ (total $9.7 \pm 1.9 \%$ ) in mucosal homogenates $(n=6)$, and $1.5 \pm 0.2,0.5 \pm$ $0.1,0.3 \pm 0.1,0.9 \pm 0.1$ and $1.2 \pm 0.3 \%$ (total $4.6 \pm 0.2 \%$ ) in muscle homogenates $(n=4)$, respectively. Elimination of GSH from the reaction mixture resulted in a marked decrease of compound IV (to 0.9 \pm 0.1 ) with a concurrent increase of compound I (to $5.6 \pm 0.2)$ in the mucosa $(\mathrm{n}=$ 3 ), whereas the pattern of products in the muscle $(n=4)$ was not affected by omission of GSH.

Fig. 2 shows the time course of the formation of various arachidonate metabolites in the presence of GSH. In the mucosa the major compounds I and IV increased with time for $60 \mathrm{~min}$, and the 


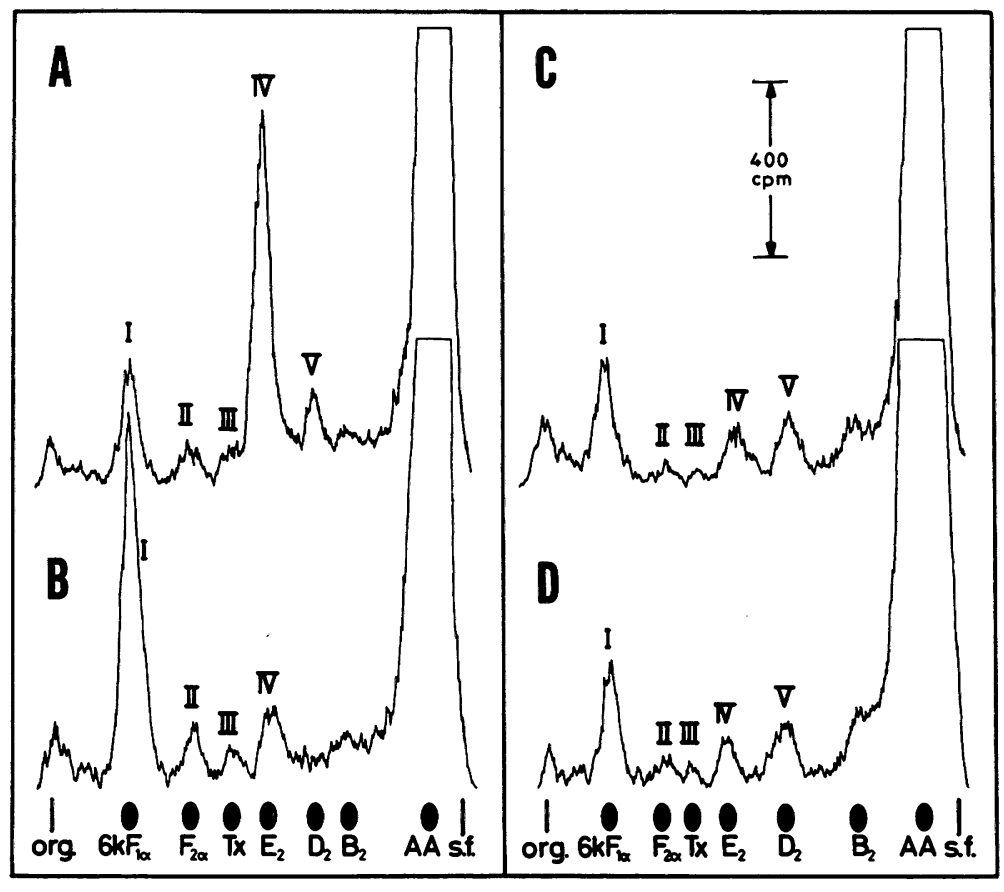

Fig. 1. Arachidonic acid transformation by homogenates of bovine gallbladder mucosa or muscle. $\left[1-{ }^{14} \mathrm{C}\right] \mathrm{AA}$ was incubated with homogenates of gallbladder mucosa (A, B) or muscle (C, D) under standard conditions in the presence $(A, C)$ or absence $(B, D)$ of glutathione. TLC plates were developed twice as described in Materials and Methods. Abbreviation: $6 \mathrm{KF}_{1 \alpha}=6$-keto-prostaglandin $\mathrm{F}_{1 \alpha} ; \mathrm{F}_{2 \alpha}$, $\mathrm{E}_{2}, \mathrm{D}_{2}$ and $\mathrm{B}_{2}=$ prostaglandin $\mathrm{F}_{2} \alpha, \mathrm{E}_{2}, \mathrm{D}_{2}$ and $\mathrm{B}_{2} ; \mathrm{TxB}_{2}=$ thrombox ane $\mathrm{B}_{2}$; org = origin and s.f. = solvent front.

minor compounds II, III and V increased for $20 \mathrm{~min}$ reaching a plateau. In the muscle the major product was compound I, which increased depending on the reaction time at least for $60 \mathrm{~min}$.

The amount of the major compounds formed for $5 \mathrm{~min}$ increased in proportion to the amount of enzyme protein up to $40 \mathrm{mg}$. The proportionality was less clear for the minor compounds. A boiled preparation of tissue homogenates produced none of these compounds. Formation of these five products was inhibited by $28 \mu \mathrm{M}$ indomethacin. Generation of compound I was inhibited by $40 \mu \mathrm{M} 15$-HPAA, an inhibitor of $\mathrm{PGI}_{2}$ synthetase (Gryglewski et al. 1976), and formation of compound III was prevented by $5 \mathrm{mM}$ imidazole, an inhibitor of $\mathrm{Tx}$ synthetase.

For identification of these products chemical convension and GC-MC analyses were performed. Compound IV was completely converted by $\mathrm{NaBH}_{4}$ treatment to materials cochromatographing with $\mathrm{PGF}_{2} \beta$ and $\mathrm{PGF}_{2} \alpha$ on TLC in the proportion of 1:1.5. The compound was quantitatively converted by methanolic $\mathrm{KOH}$ treatment to a material corresponding to $\mathrm{PGB}_{2}$. These chemical conversions were confirmed with authentic $\left[{ }^{3} \mathrm{H}\right]-\mathrm{PGE}_{2}$ as positive controls. GC-MS of compounds I and IV after derivatization showed mass spec- 


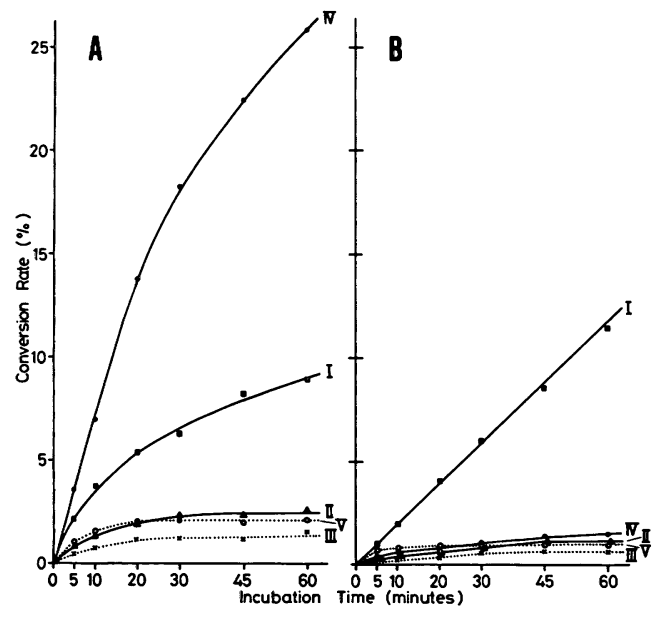

Fig. 2. Time courses of AA transformation in gallbladder. Standard reaction mixtures including homogenates of bovine gallbladder mucosa (A) or muscle (B) were incubated in the presence of GSH for the times indicated. Vertical axis indicates coversion rate (mean of 3 experiments) expressed as percentage of the total radioactivity recovered from the TLC plate.

--1: compound I (6-keto-PGF $1 \alpha$ ), $\Delta-\Delta-\Delta$ : compound II ( $\mathrm{PGF}_{2} \alpha$-like material), $\times \cdots \times \cdots \times:$ compounds III $\left(\mathrm{TxB}_{2}-\right.$ like material), $\bullet-\bullet-$ : compound IV $\left(\mathrm{PGE}_{2}\right)$, and $\circ \cdots \circ \cdots \circ$ : compound V ( $\mathrm{PGD}_{2}$-like material). tra identical with those of authentic 6 keto-PGF ${ }_{1} \alpha$ and $\mathrm{PGE}_{2}$ derivatized in the same way (Fig. 3). The molecular ion and major fragments are in agreement with those reported earlier for the methyl ester-methoxime-trimethylsilyl ether derivative of each corresponding prostaglandin (Gréen, 1969; Chang and Morita, 1977), The amounts of compounds II, III and V were not sufficient for GC-MS.

\section{Discussion}

These data indicate that bovine gallbladder mucosa produced predominantly $\mathrm{PGE}_{2}$ and $\mathrm{PGI}_{2}$ with lesser amounts of $\mathrm{PGF}_{2} \alpha-, \mathrm{TxB}_{2}-$ and $\mathrm{PGD}_{2}$-like materials from AA. Furthermore, the predominant product is $\mathrm{PGE}_{2}$ in the presence of GSH and $\mathrm{PGI}_{2}$ in its absence.

The requirement of GSH is a specific property of PGE synthetase. Inhibition by 15-HPAA and imidazole is characteristic of $\mathrm{PGI}_{2}$ synthetase and $\mathrm{TXB}_{2}$ synthetase, respectively. GSH dependency was not clear in the production of $\mathrm{PGD}_{2}$ like material. Enzymes involved in the
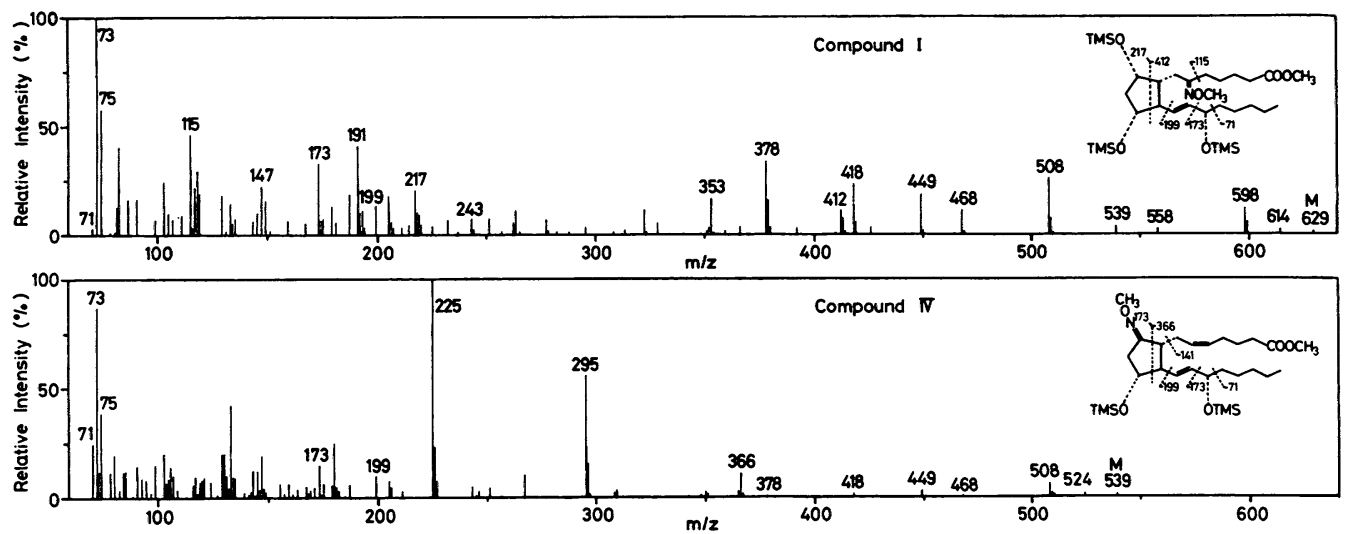

Fig. 3. Mass spectra of major arachidonate metabolites in gallbladder mucosa. Methyl ester-methoxime-trimethylsilyl ether derivatives of compounds I and IV formed by incubation of $20 \mu \mathrm{M}$ AA with homogenates of bovine gallbladder mucosa was subjected to GC-MS as described in Materials and Methods. The lower panel shows a spectrum of the major isomer of the derivatized compound IV. 
generation of $\mathrm{PGF}_{2} \alpha$ - and PGD-like materials from $\mathrm{PGH}_{2}$ remain uncertain.

Recent reports (Nakata et al. 1981; Michael et al. 1983) demonstrated that in guinea-pig gallbladders AA was converted predominantly to $\mathrm{PGE}_{2}$ and to $\mathrm{PGF}_{2} \alpha$, 6 -keto- $\mathrm{PGF}_{1} \alpha$ and $\mathrm{TxB}_{2}$ to a lesser extent. The enzyme preparation used in this study was a homogenate of gallbladders containing morphologically and functionally different layers such as mucosa, muscle and serosa. Inflammed human gallbladders were shown in bioassay to produce PG-like material(s) in different amounts in different layers (Wood and Stanford, 1977). We have now shown that in normal bovine gallbladders the enzymatic capacity to produce PGs in the mucosa is significantly (more than 2 times) higher than in the muscle and that the quantitative pattern of PG production in the mucosa is different from that in the muscle which produces predominantly $\mathrm{PGI}_{2}$ and to a lesser extent $\mathrm{PGF}_{2} \alpha$ - and $\mathrm{PGE}_{2}$-like material (Nakano et al. 1983). GSH availability may control the production of either $\mathrm{PGE}_{2}$ or $\mathrm{PGI}_{2}$ as a major product.

These results on the biosynthetic capacity for PGs in the mucosa and muscle should provide a basis for future investigations of the role of PGs in physiological and pathological conditions of the gallbladder.

Acknowledgments: We are greatful to Dr. S. Yamamoto for critically reading the manuscript. We also thank the Ono Pharmaceutical Company for a generous supply of synthetic prostaglandins, thromboxane $\mathrm{B}_{2}$ and 15-HPAA. This work was supported in part by a grantin-aid from the Ministry of Education, Science and Culture of Japan, and by a research grant from the Ishibashi Foundation.

\section{References}

Chang, W-C. and Murota, S-I. (1977). Identification of 6-keto-prostaglandin $F_{1 \alpha}$ formed from arachidonic acid in bovine seminal vesicles. Biochim. Biophys. Acta. 486, 136-144.

GREEN, K. (1969). Gas chromatography-mass spectrometry of $\mathrm{O}$-methyloxime derivatives of prostaglandins. Chem. Phys. Lipids 3, 254-272.

Gryglewsit, R. J., Bunting, S., Moncada, S., Flower, R.J. and VANE, J.R. (1976). Arterial walls are protected against deposition of platelet thrombi by a substance (prostaglandin $\mathrm{X}$ ) which they make from prostaglandin endoperoxides. Prostaglandins 12, 685-713.

LeE, S.P., Carey, M.C. and LaMont, M. T. (1981). Aspirin prevention of cholesterol gallstone formation in prairie dogs. Science 211, 14291431.

Michael, L., Booker, B.S. and LaMort, W.W. (1983). Prostaglandin release from in vitro guinea-pig gallbladder. Prostaglandins 25, 143-153.

Morton, I.K.M., Saveymuttu, S.H. and Wood, J.R. (1974). Inhibition by prostaglandins of fluid transport in the isolated gallbladder of the guinea-pig. Br. J. Pharmacol. 50, 460461.

Nakano, M., Hidaka, T., Ueta, T. and Ogura, R. (1983). Arachidonate metabolism in bovine gallbladder muscle. Prostaglandins 25, 503510.

NakATA, K., Ashida, K., Nakazawa, K. and Fujiwara, H. (1981). Effects of indomethacin on prostaglandin synthesis and on contractile response of the guinea pig gallbladder. Pharmacology 23, 95-101.

Wood, J.R. and Stamford, I.F. (1977). Prostaglandins in chronic cholecystitis. Prostaglandins 13, 97-106. 